\title{
Aprofitant cada engruna de calor: el Tub Verd de Mataró
}

\author{
Llorenç Alerm \\ Gerent de Mataró Energia Sostenible S.A. (MESSA)
}

La calor residual de diverses infraestructures mediambientals permet distribuir calor $i$ fred al seu entorn urbà. Es tracta d'un aprofitament energètic que redueix contaminació, emissions de $\mathrm{CO}_{2}$ i importacions de combustible. Una estratègia que fa anys que funciona a diversos països del món: al centre i nord d'Europa fa temps que hi està força estesa, $i$ més recentment ha arribat aquí, amb iniciatives com la del Tub Verd de Mataró.

Paraules clau: calor residual, xarxes de calor i de fred, district heating \& cooling, refrigeració per absorció

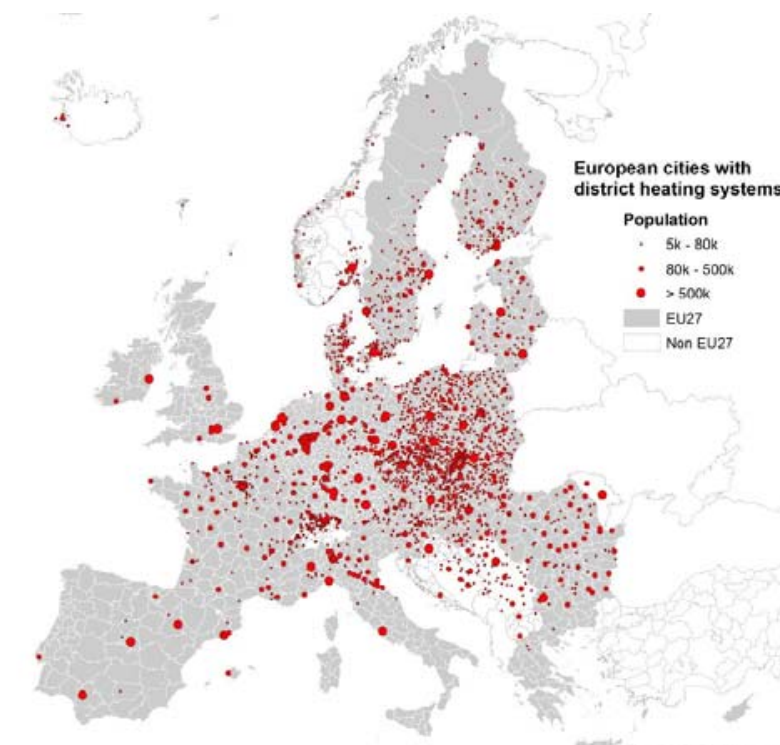

Figura 1. Xarxes de distribució de calor a Europa. La mida de cada punt està relacionada amb la població de la ciutat. (Connolly i al., 2012)

Reduir la factura i la dependència energètica, així com les emissions de $\mathrm{CO}_{2}$ són necessitats cada vegada més imperioses.

Una de les estratègies és esprémer al màxim cada joule d'energia que consumim. Si amb aquesta idea al cap mirem les grans instal-lacions de tractament de la brossa i de l'aigua residual, veurem que una bona part de l'energia que s'hi gestiona acaba convertida en calor a una temperatura prou elevada com per poder aprofitar-la.

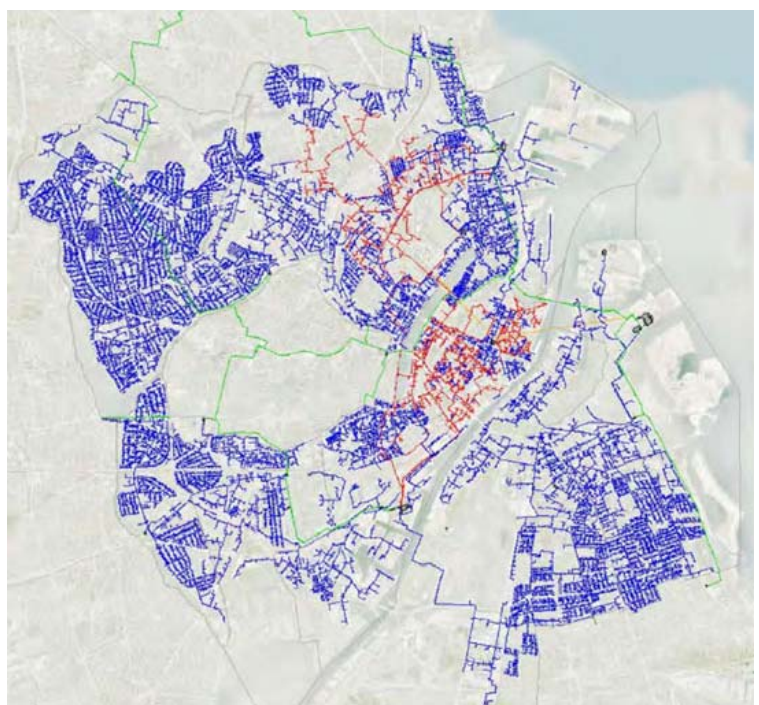

Figura 2. Xarxa de distribució de calor a la ciutat a de Copenhaguen, Dinamarca. Significa una disminució d'emissions de $\mathrm{CO}_{2}$ del $40-50 \%$ (Elsman, 2009).

Aquesta idea s'ha materialitzat a molts llocs del món en forma de xarxes de distribució de calor a l'entorn urbà, anomenades district heating (figs. 1 i 2).

\section{El Tub Verd de Mataró}

Mataró disposa de dues grans instal-lacions mediambientals properes entre si: el Centre de Trac- 
tament i Valoració de Residus Sòlids Urbans, amb una instal-lació d'incineració de residus municipals (entre altres processos de tractament), i l'Estació Depuradora d'Aigües Residuals (EDAR) del Maresme central. En el seu procés, l'EDAR genera fangs biològics que es sotmeten a digestió anaeròbia, amb producció de biogàs. La calor generada per la incineradora i la invertida en els fangs es podia deixar perdre... o bé aprofitar-la. Aquesta segona opció ens estalviava contaminació, emissions de $\mathrm{CO}_{2}$ i també diners.

Per aprofitar aquesta oportunitat es va constituir el 2001 una nova empresa, MESSA (Mataró, Energia Sostenible, S.A.). Actualment el seu capital social és de $4200000 €$, amb la següent distribució:

- 65 \% d'una empresa municipal (Aigües de Mataró S.A.)

- $25 \%$ d'una empresa de la Generalitat (Eficiència Energètica S.A., ICAEN, del Departament d'Economia)

- $10 \%$ d'un organisme estatal (Instituto para la Diversificación y Ahorro de la Energía, del Ministeri d'Indústria)

La inversió realitzada fins ara és d'11,3 milions d'euros. La facturació del 2011 va ser de 3,5 mili- ons. La plantilla de MESSA és de 5 persones qualificades; com que tots els processos estan automatitzats, la seva funció principal és de control i manteniment de les instal-lacions actuals, així com l'estudi i disseny tant de noves fonts com de noves connexions.

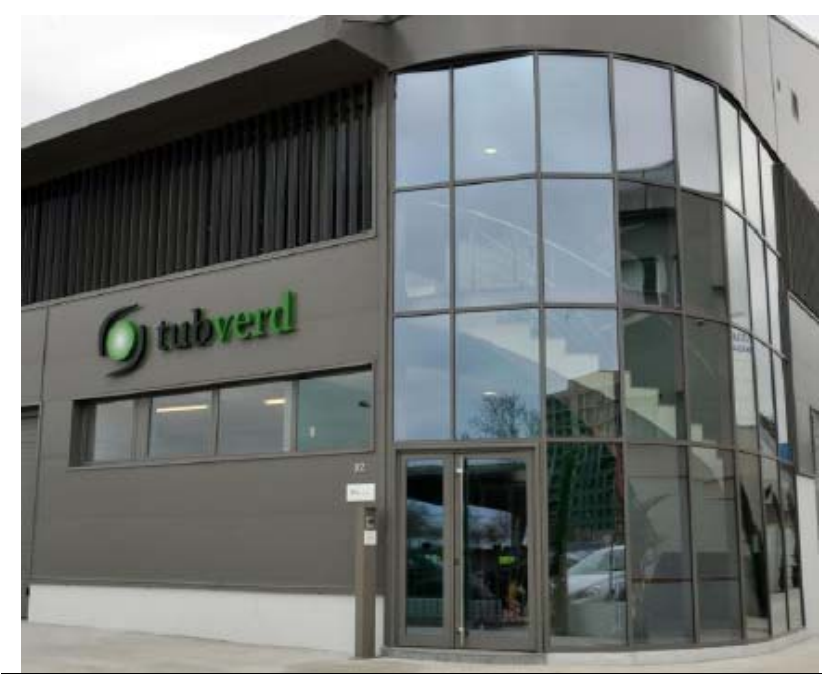

Figura 3. Seu de l'empresa MESSA, que gestiona el Tub Verd de Mataró.

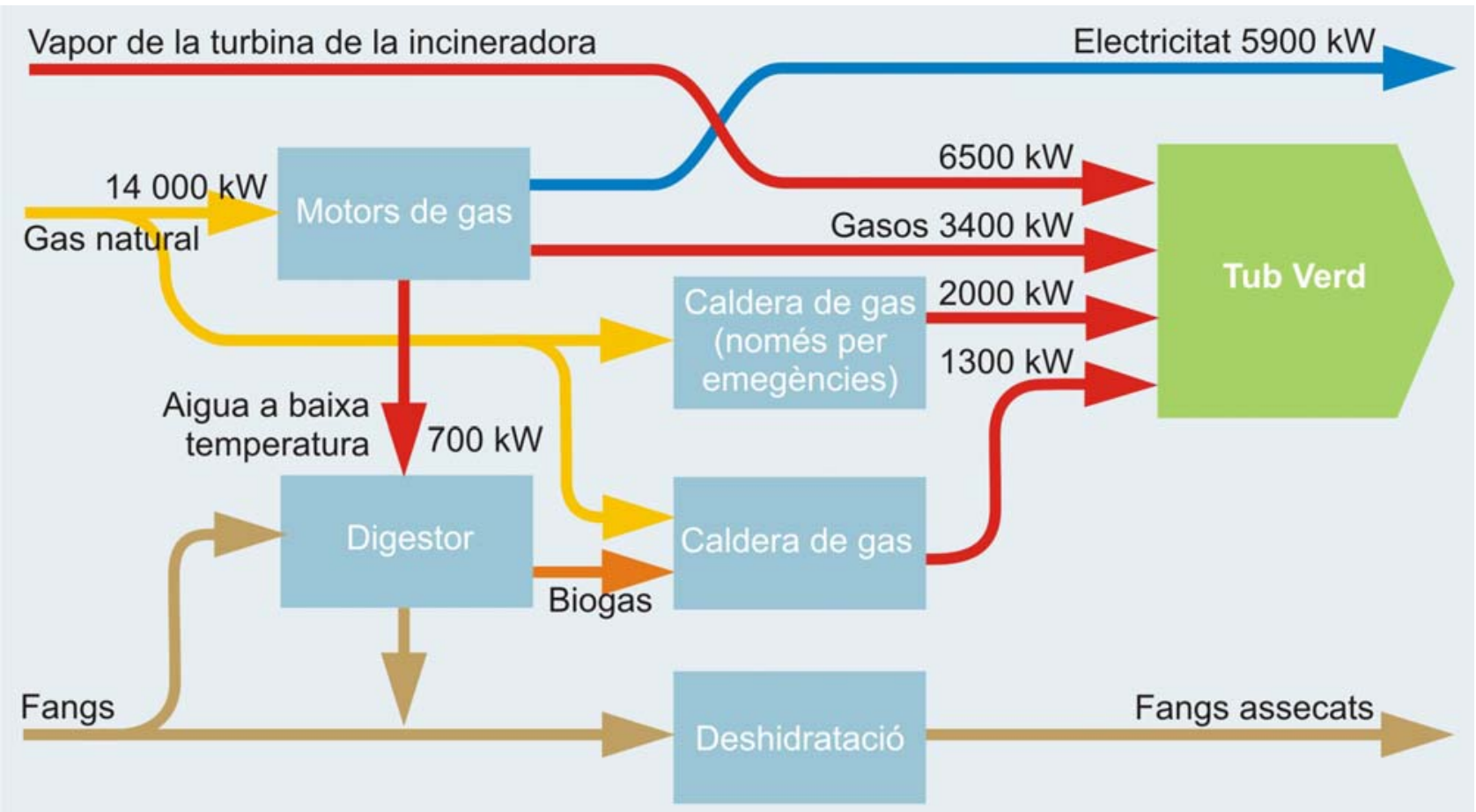

Figura 4. Fluxos d'energia i materials a l'EDAR i a la central del Tub Verd. Hi acaben aportant una potència calorífica mitjana al llarg de l'any d'uns 9000 kW. 


\section{Origen de la calor aprofitada}

La planta de secat de fangs de l'EDAR consumeix gas natural per fer anar els motors que necessita per al seu funcionament. En un procés de cogeneració es produeix electricitat al mateix temps que s'utilitza la calor per escalfar els digestors de fangs, mentre que la calor excedent s'aporta al Tub Verd.

El biogàs que s'ha obtingut en la digestió dels fangs conté un $60 \%$ de metà. Quan es crema, mitjançant una caldera amb cremador especial modulant, genera calor que també s'aprofita al Tub Verd.

\section{El transport de la calor fins a l'usuari}

Tractant-se d'una tecnologia que, com hem vist, té una gran implantació a molts països europeus, no resulta cap problema trobar proveïdors dels tubs (fig. 5), derivacions, vàlvules, bescanviadors, etc.

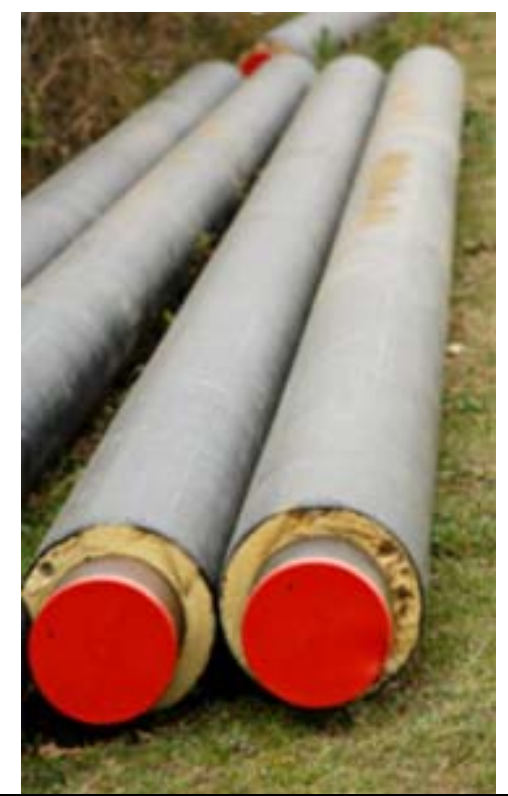

Figura 5. Detall dels tubs de distribució que s'enterren al carrer. S'hi pot veure l'aïllant.

La xarxa de distribució del Tub Verd de Mataró tenia fins al 2008 una llargada de 14 km, proporcionant més de $9 \mathrm{GWh} /$ any a 15 equipaments públics, situats sobretot a la part alta de la ciutat: un centre d'esports, escoles, instituts, la piscina i l'hospital. Això va suposar obrir els carrers (fig. 6) per fer-hi passar els dos tubs: un amb aigua calenta que surt de la planta a $90-95^{\circ} \mathrm{C}$ i l'altre que la retorna a uns $60-70^{\circ} \mathrm{C}$.

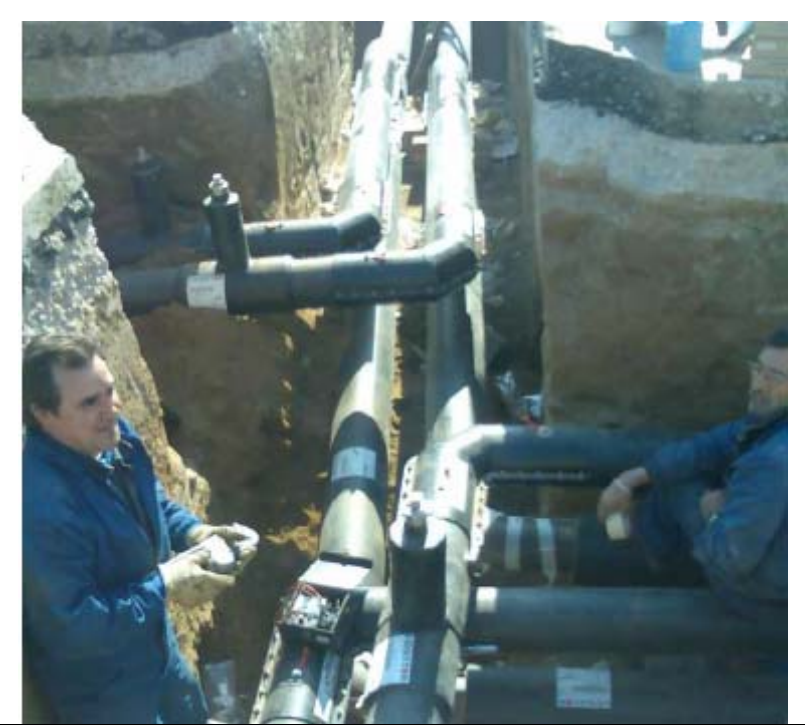

Figura 6. Obres d'allargament de la primera xarxa de distribució, el 2009.

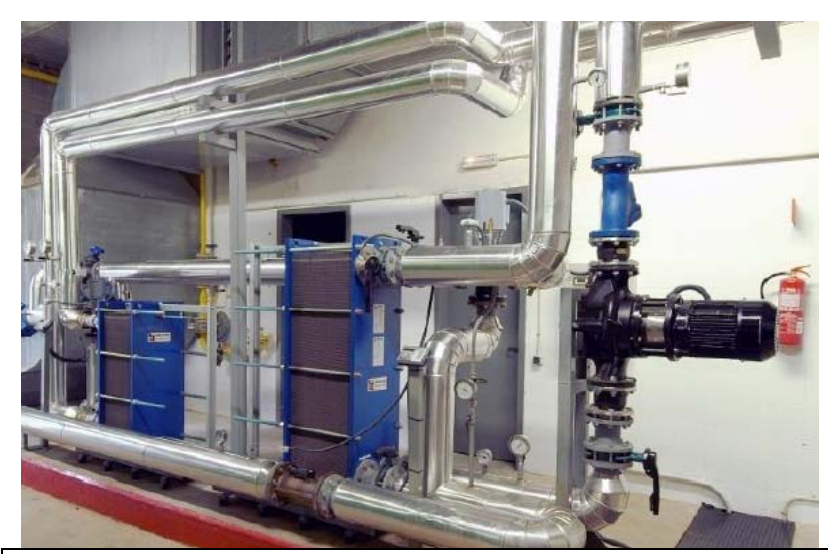

Figura 7. Els dos bescanviadors de calor a l'hospital de Mataró, de 600 i 1500 kW de potència.

Un cop el tub arriba amb aigua calenta fins a l'usuari final, cal un bescanviador (fig. 7) per transferir l'energia tèrmica al circuit d'aigua interior a l'edifici, que és la que circula pels radiadors de l'edifici i escalfa l'aigua calenta sanitària.

Per mantenir constantment l'aigua en circulació s'utilitzen bombes centrífugues amb motors elèctrics controlats amb variadors de velocitat per optimitzar el seu consum, que consumeixen $800 \mathrm{MWh}$ anuals.

En un escenari final, en conjunt tot el sistema del Tub Verd subministrarà anualment 43,91 GWh d'energia tèrmica, equivalent al consum de 7000 famílies. Comparat amb els sistemes convencionals, això suposa una reducció de les emissions de $\mathrm{CO}_{2}$ de 10800 tones anuals, una reducció equivalent a plantar 2500 noves hectàrees de bosc, una 
superfície similar a gairebé quatre vegades l'àrea urbana de Mataró.

\section{Xarxa de distribució de calor ...i de fred?}

Si al nord d'Europa les xarxes de distribució de calor són necessàries a causa del seu clima, a la nostra latitud es fa convenient també disposar de fred per als mesos d'estiu. Per això, actualment la xarxa del Tub Verd es completa amb un altre circuit a la nova part baixa de la ciutat que a més a més de calor també proporciona fred (fig. 8). Això fa necessària la instal-lació de quatre tubs: dos per a la calor i dos per al fred (fig. 9).

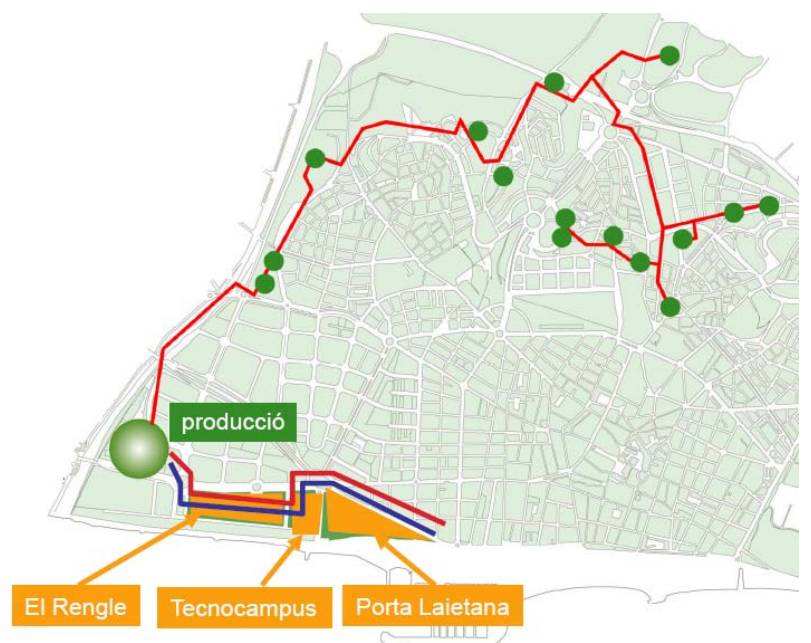

Figura 8. La primera xarxa proporcionava calor a 15 equipaments de la part alta de Mataró. La nova xarxa, que serveix la part costanera de nova urbanització, hi subministra calor i fred.

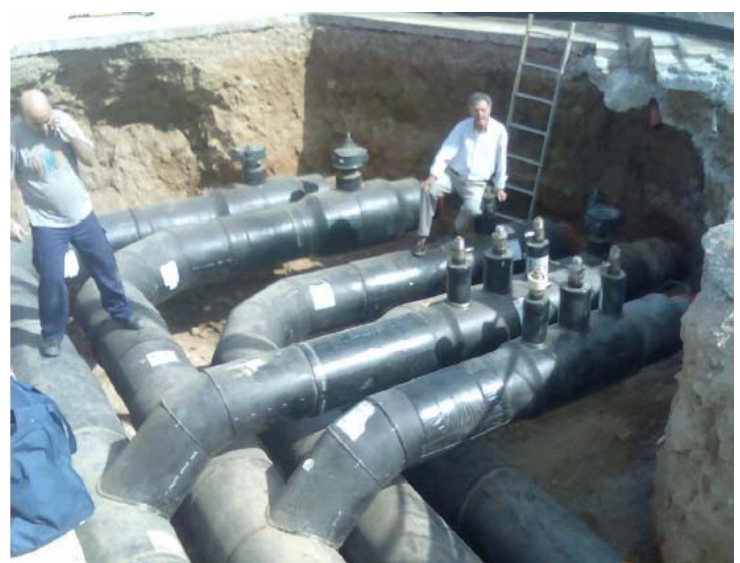

Figura 9. Instal-lació de la nova xarxa del Tub Verd per distribuir calor i fred.

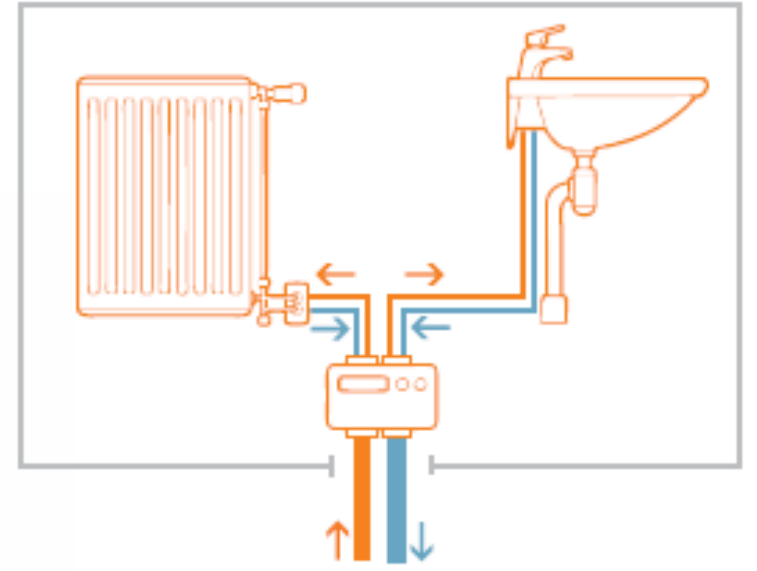

Figura 10. Bescanviador de calor per proporcionar calefacció i aigua calenta a una llar.

La urbanització d'una nova zona de la ciutat ha proporcionat l'ocasió per connectar ja des del principi els habitatges a la nova xarxa del Tub Verd. Els usuaris domèstics disposen d'uns bescanviadors adequats a les seves necessitats de climatització (fred i calor) i d'aigua calenta sanitària (fig. 10).

Actualment el Tub Verd genera el fred mitjançant dues màquines turbocompressores de velocitat variable, amb una capacitat total de $5 \mathrm{MW}$.

A curt termini es preveu la incorporació d'una nova màquina d'absorció de simple efecte de 2 MW, que produeix fred a partir de calor.

\section{Obtenir fred a partir de calor?}

Si la font d'energia del Tub Verd és bàsicament la calor residual d'unes instal-lacions, sembla impossible que se'n pugui generar fred. Però no ho és: actualment la tecnologia permet obtenir fred a partir de calor utilitzant enginyosament alguns principis físics com els següents:

- L'evaporació d'aigua absorbeix calor de l'entorn, refredant-lo.

- Aquesta evaporació es pot afavorir a baixa pressió.

- Hi ha dissolucions, com les de bromur de liti en aigua, capaces d'absorbir una gran quantitat de vapor d'aigua quan són prou concentrades.

La dissolució de bromur de liti absorbeix vapor d'aigua (fig. 12), contribuint a mantenir baixa la pressió en el recipient (evaporador - absorbidor) i a continuar, doncs, el procés d'evaporació d'aigua que absorbeix calor dels tubs per on circula l'aigua. 
Per altra banda, el circuit intern es completa amb un recipient (generador) on la dissolució diluïda de bromur de liti rep calor externa per evaporar l'aigua que s'hi ha incorporat. Aquest vapor és refredat (en el condensador) mitjançant l'aigua procedent de la torre de refrigeració, per ser de nou evaporada, tancant el cicle.

El balanç energètic del sistema apareix a la fig. 11: la calor que s'extreu del circuit d'aigua és igual a la calor dissipada a la torre de refrigeració menys la calor aportada pel vapor extern.

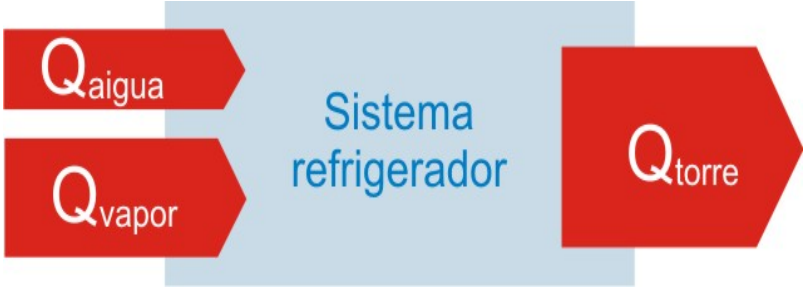

Figura 11. Balanç tèrmic del sistema generador de fred: la calor extreta de l'aigua, juntament amb la del vapor s'ha de dissipar a la torre de refrigeració.

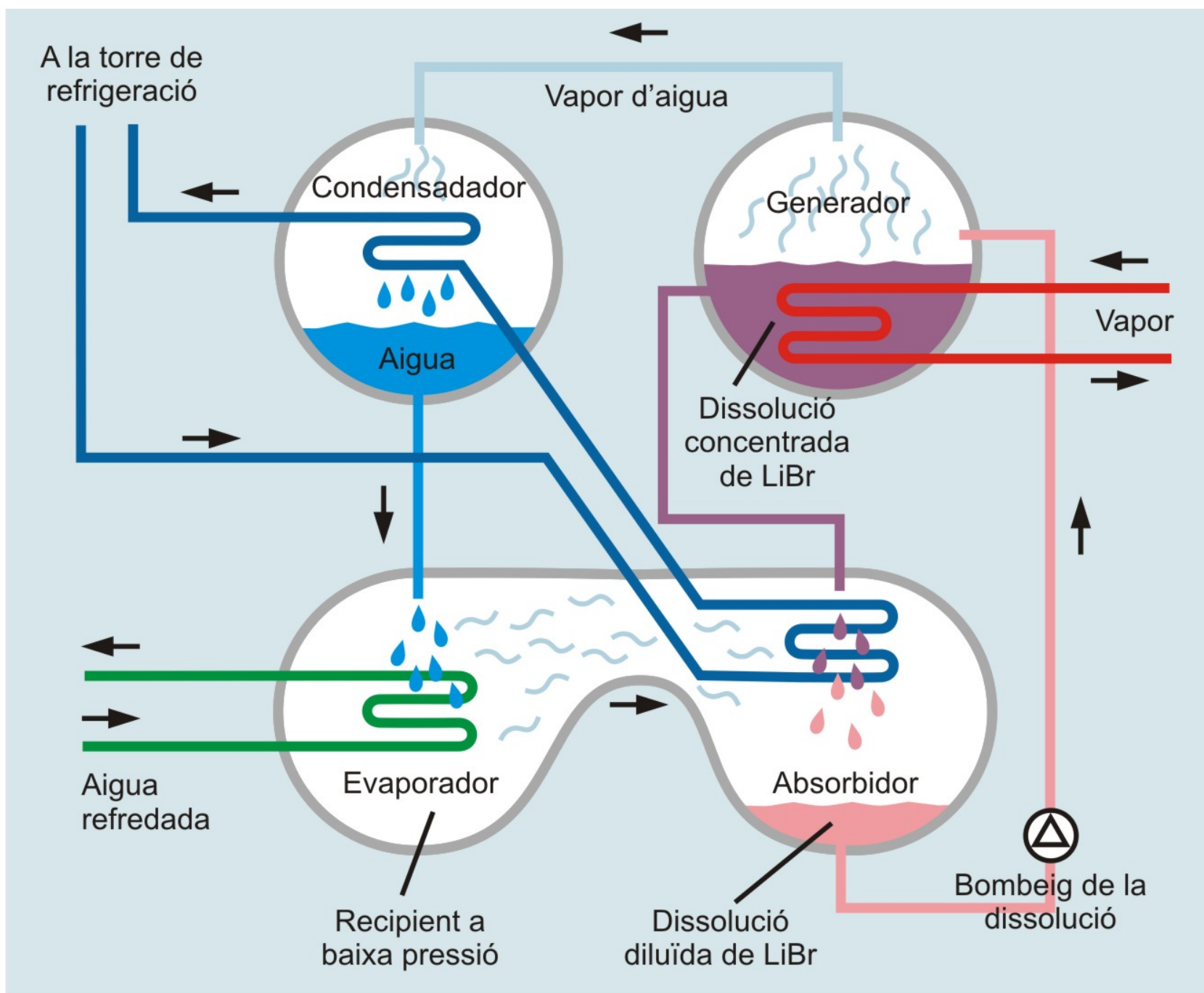

Figura 12. Diagrama de funcionament d'una estació de refrigeració basada en absorció de vapor d'aigua mitjançant una dissolució concentrada de bromur de liti. 


\section{També a Barcelona}

La reurbanització de la zona del Fòrum a Barcelona va suposar la oportunitat per instal.lar la primera xarxa de distribució de calor (fig. 13) a la capital catalana, sobretot a la zona del Poblenou i districte 22@, utilitzant vapor de la planta de tractament de residus sòlids urbans de Sant Adrià. També hi ha una altra xarxa a la banda de la Zona Franca que aprofita el fred generat en la regasificació del gas liquat al port. Actualment està en fase de projecte una xarxa a la Sagrera.

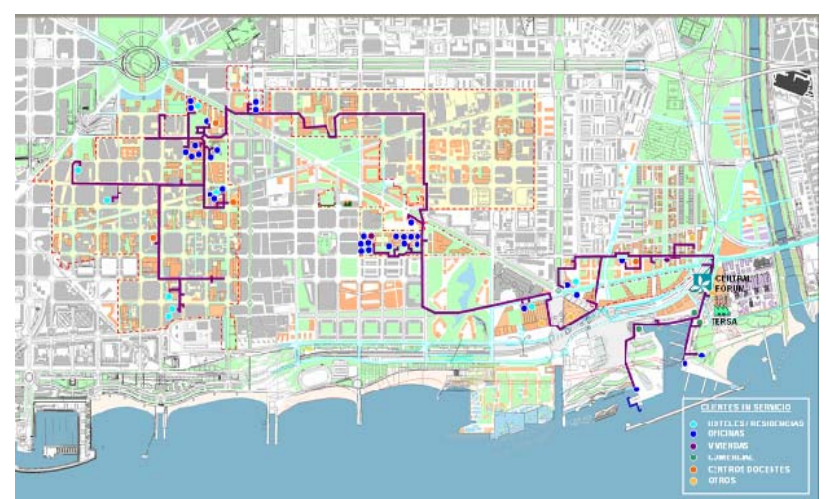

Figura 13. Xarxa de distribució de Districlima S.A. a Barcelona i localització dels principals clients.

\section{Avantatges de les xarxes de calor i de fred}

- S'aprofiten energies residuals d'instal-lacions mediambientals, mitjançant equips d'alt rendiment energètic, fent disminuir el consum d'energies primàries d'origen fòssil i la dependència energètica del territori.
- Beneficiós mediambientalment al disminuir les emissions de $\mathrm{CO}_{2}$ contribuint a evitar el canvi climàtic.

- S'eviten les pèrdues de refrigerant a l'atmosfera, sempre possibles en els sistemes de refrigeració convencionals.

- Suposa un estalvi econòmic per al client, ja que el preu és a l'entorn d'un $10 \%$ inferior al de sistemes convencionals, amb tendència futura favorable.

- L'estalvi augmenta amb el temps perquè la reducció del rendiment dels equips generadors de calor o fred individuals, que faria consumir més energia primària amb equips convencionals, no es dóna amb l'energia del tub verd. Amb el tub verd es consumeix directament energia útil.

- Disminueixen els sorolls i vibracions en els edificis connectats al sistema.

- Calefacció i fred més confortable ja que no resseca l'ambient. La confortabilitat de la calor depèn de l'elecció d'elements terminals. Si es fa amb fan-coils sí que resseca l'ambient. L'augment de confort es nota més amb el fred. La generació de fred amb fan-coil en lloc de l'split és més confortable perquè les temperatures d'impulsió d'aire són més properes a les de confort. Al no refredar tant l'aire no perd tanta aigua i el confort ambiental augmenta.

- El manteniment a càrrec de l'empresa suposa una comoditat per a l'usuari final.

- L'impacte visual és nul, ja que els terrats i les façanes dels usuaris queden totalment netes d'instal-lacions.

\section{Bibliografia}

Connolly, D. i al. (2012). Heat Roadmap Europe 2050 (Pre-study). web

Elsman, P (2009). Copenhagen district heting system. web 